Оценка эффективности фиксированной комбинации периндоприла и амлодипина у больных ишемической болезнью сердца, перенесших операцию аортокоронарного шунтирования

\author{
Б.Г. Искендеров*, О.Н. Сисина, О.А. Каменева
}

ГОУ АПО Пензенский институт усовершенствования врачей. Пенза, Россия

\title{
Effectiveness of the fixed-dose combination therapy with perindopril and amlodipine in coronary heart disease patients after coronary artery bypass graft surgery
}

\author{
B.G. Iskenderov*, O.N. Sisina, O.A. Kameneva \\ Penza Institute of Post-diploma Medical Education. Penza, Russia
}

\begin{abstract}
Цель. Изучить эффективность фиксированной комбинации периндоприла и амлодипина (Престанс 5/5 мг/сут.) у больных ишемической болезнью сердца (ИБС), перенесших аортокоронарное шунтирование (АКШ).

Материал и методы. В клиническое исследование были включены 65 больных (37 мужчин и 28 женщин) в возрасте 45-68 лет (средний возраст 56,3土3,5), перенесших АКШ. Больные были рандомизированы на 2 группы (гр.): контрольная гр. - ГК $(\mathrm{n}=35)$ и основная гр. - ОГ $(\mathrm{n}=30)$. Больные обеих гр. получали дезагреганты и статины, в ОГ дополнительно назначался Престанс $5 / 5$ мг/сут. Престанс назначали через 3-4 нед. после АКШ и в течение 4 мес. Больным проводили суточное мониторирование (СМ) ЭКГ и АД, допплер-эхокардиографию, допплеровское исследование плечевой и общей сонной артерий.

Результаты. Престанс 5/5 мг/сут. по сравнению с КГ достоверно уменьшает количество эпизодов болевой и безболевой ишемии миокарда, максимальную депрессию сегмента ST и ее суммарную продолжительность, увеличивает частотный порог возникновения ишемии. Престанс улучшает систолическую и диастолическую функции сердца, достоверно увеличивает величину эндотелий-зависимой вазодилатации. На фоне нормального АД он не вызывает нагрузки гипотензией, но снижает избыточную вариабельность (Вар) АД. В ОГ острый коронарный синдром возник у 1 (3,3\%) больного, в ГК - у 4 (11,4 \%) и в 3 случаях проводилось стентирование коронарных артерий.

Заключение. Лечение Престансом 5/5 мг/сут., начатое в ближайшем послеоперационном периоде АКШ, у больных с нормальным АД оказывает выраженный противоишемический, кардио- и вазопротективный эффекты, предупреждает высокую суточную Вар АД.
\end{abstract}

Ключевые слова: Престанс, периндоприл, амлодипин, аортокоронарное шунтирование, фиксированные комбинации лекарств.

Aim. To study the effectiveness of the fixed-dose combination therapy with perindopril and amlodipine (Prestance $5 / 5 \mathrm{mg} / \mathrm{d}$ ) in coronary heart disease (CHD) patients after coronary artery bypass graft (CABG) surgery.

Material and methods. The clinical trial included 65 patients ( 37 men, 28 women aged 45-68 years; mean age $56,3 \pm 3,5$ years $)$ after CABG. All patients were randomised into two groups: the control group $(\mathrm{CG} ; \mathrm{n}=35)$ and the main group $(M G ; n=30)$. Both groups received antiplatelet agents and statins, while the MG patients additionally received Prestance $(5 / 5 \mathrm{mg} / \mathrm{d})$. Prestance therapy started three-four weeks after CABG and lasted for four months. All participants underwent 24-hour monitoring of ECG and blood pressure (BP), Doppler echocardiography, and Doppler ultrasound of brachial and common carotid arteries.

Results. Compared to the CG, the MG demonstrated decreased incidence of pain and painless ischemia episodes,

\footnotetext{
(с)Коллектив авторов, 2011

E-mail: iskenderovbg@mail.ru

Тел.: 906-399-56-72
}

[Искендеров Б.Г. (*контактное лицо) - профессор кафедры терапии, кардиологии и функциональной диагностики, Сисина О.Н. - заведующая кафедрой нефрологии, Каменева О.А. - врач-кардиолог отделения кардиологии № 3 Пензенской городской клинической больницы скорой медицинской помощи] 
reduced maximal ST segment depression and its total duration, and increased rate threshold of myocardial ischemia. In addition, Prestance therapy was associated with improved systolic and diastolic heart function and significantly improved endothelium-dependent vasodilatation. In patients with normal BP, Prestance $(5 / 5 \mathrm{mg} / \mathrm{d})$ did not cause hypotension, but reduced excessive BP variability. In the MG, acute coronary syndrome (ACS) was registered in 1 individual (3,3\%), while in the $\mathrm{CG}$, it was registered in 4 patients $(11.4 \%)$, and in 3 cases, coronary artery stenting was performed.

Conclusion. In patients with normal BP, Prestance $(5 / 5 \mathrm{mg} / \mathrm{d})$ therapy in the early post-CABG period had a pronounced anti-ischemic, cardio- and vasoprotective effects, and also prevented excessive BP variability.

Key words: Prestance, perindopril, amlodipine, coronary artery bypass graft surgery, fixed-dose combination therapy.

Хирургическое вмешательство у больных с осложненными формами ишемической болезни сердца (ИБС): поражение ствола левой коронарной артерии (КА), нестабильная стенокардия (НС), низкая сократительная функция миокарда, обусловленная его ишемией и рубцовой деструкцией, нарушение геометрии камер сердца вследствие постинфарктных аневризм, разрыва межжелудочковой перегородки (МЖП) и митральной недостаточности, служит единственно эффективным средством улучшения прогноза таких больных [3]. При этом важно отметить, что лечение не должно останавливаться на получении первичных, даже самых обнадеживающих результатов, поскольку хирургическая реваскуляризация не оказывает непосредственного влияния на атеросклероз в целом, а только обеспечивает надежную профилактику осложнений ИБС.

Операция аортокоронарного шунтирования (АКШ) устраняет первый барьер, т. е. сужение или окклюзию КА для восстановления кровоснабжения поврежденных отделов миокарда, однако, как правило, после реваскуляризации миокарда в результате комплекса причин восстановление функции и регресс признаков повреждения замедляются $[3,5]$. Причинами этого могут быть реперфузинное повреждение кардиомиоцитов (КМЦ), развитие острой или прогрессирующей сердечной недостаточности $(\mathrm{CH})$ после устранения постинфарктных аневризм левого желудочка (ЛЖ). Коагуляционные нарушения и повреждение стенки трансплантата в ходе операции создают предпосылки для развития пери- и послеоперационного инфаркта миокарда (ИМ) [3]. Известно, что первые 2-3 нед. после АКШ, несмотря на отсутствие типичных ангинозных приступов, может регистрироваться ишемическая депрессия сегмента ST до 1,5 мм. У больных, перенесших АКШ, и с пониженной пороговой мощностью физической нагрузки $(Ф Н)$ и фракцией выброса $(Ф В)$ в $70 \%$ случаев присутствует низкий коронарный резерв [5]. Все это подчеркивает важность и необходимость проведения реабилитации больных, перенесших АКШ, включая рациональное медикаментозное лечение, позволяющее обеспечить максимально возможный терапевтический эффект и наилучший прогноз.

В связи с этим представляется актуальным выбор лекарственных препаратов (ЛП), имеющих серьезную доказательную базу в отношении снижения риска сердечно-сосудистых осложнений (ССО) и смертности. У больных артериальной гипертензией (АГ) в сочетании с ИБС (АГ + ИБС) в многоцентровых, рандомизированных, клинических исследованиях доказана высокая эффективность антагонистов кальция (AK) [1,9] и ингибиторов ангиотензин-преврашающего фермента (ИАПФ).

В клинических исследованиях CAMELOT (Comparison of Amlodipine vs Enalapril to Limit Occurrences of Thrombosis) и PREVENT (Prevention of Recurrent Venous Thromboembolism) у больных со стабильной ИБС и нормальным артериальным давлением (АД) получены убедительные доказательства того, что амлодипин значительно замедляет прогрессирование коронарного атеросклероза и, тем самым, достоверно снижает риск развития ССО, сердечной смертности и частоту выполнения хирургической реваскуляризации $[19,20]$. В рандомизированных, клинических исследованиях ASCOT (Anglo-Scandinavian Cardiac Outcomes Trial), EUROPA (European trial on Reduction Of cardiac events with Perindopril in stable coronary Artery disease) и PERSPECTIVE (PERindopril's Prospective Effect on Coronary aTherosclerosis by Angiography and IntraVascular Ultrasound Evaluation) у больных ИБС, по данным коронароангиографии (КАГ), установлено антиатеросклеротическое действие периндоприла, снижение частоты коронарных событий, $\mathrm{CH}$, реваскуляризации миокарда и кардиальной смертности [7,10,21].

В многоцентровых, клинических исследованияx STRONG (Strength TRaining ONGoing study), EUROPA и ACCOMPLISH (Avoiding Cardiovascular events through Combination therapy in Patients Living with Systolic Hypertension) доказана высокая терапевтическая эффективность комбинации дигидропиридиновых АК (дАК) и ИАПФ у больных $\mathrm{AГ}+$ ИБС $[2,6,15,22]$. В рекомендациях по диагностике и лечению АГ комбинации АК и ИАПФ рассматривают как рациональные, рекомендуемые двухкомпонентные схемы лечения, что определяется их синергическими и взаимодополняющими терапевтическими эффектами, а также частичной нейтрализацией побочных эффектов (ПЭ) $[4,17,23]$. 
Клиническая характеристика больных в сравниваемых гр. (n/\%)

Таблица 1

\begin{tabular}{lll}
\hline Показатели & $\begin{array}{l}\text { ГK } \\
(\mathrm{n}=35)\end{array}$ & $\begin{array}{l}\text { ОГ } \\
(\mathrm{n}=30)\end{array}$ \\
\hline Мужчины / женщины (n) & $20 / 15$ & $17 / 13$ \\
ИМ в анамнезе & $20 / 57,1$ & $18 / 60,0$ \\
САД, мм рт.ст. $(\mathrm{M} \pm \mathrm{SD})$ & $132,4 \pm 6,6$ & $133,5 \pm 7,2$ \\
ДАД, мм рт.ст. $(\mathrm{M} \pm \mathrm{SD})$ & $87,8 \pm 3,1$ & $88,3 \pm 3,4$ \\
ХСН І-ІІ ФК & $11 / 31,4$ & $10 / 33,3$ \\
ДЛП & $16 / 45,7$ & $12 / 40,0$ \\
СД-2 & $10 / 28,6$ & $8 / 26,7$ \\
Ожирение (ИМТ $>30$ кг/м $\left.{ }^{2}\right)$ & $12 / 34,3$ & $11 / 36,7$ \\
Курильщики & $25 / 71,4$ & $23 / 76,7$ \\
& Данные КАГ & \\
монофокальное поражение & $4 / 11,4$ & $3 / 10,0$ \\
бифокальное поражение & $10 / 28,6$ & $8 / 26,7$ \\
полифокальное поражение & $21 / 60,0$ & $19 / 63,3$ \\
Количество шунтов (М $\pm \mathrm{SD})$ & $2,83 \pm 0,12$ & $2,86 \pm 0,13$ \\
Аневризмоэктомия или пластика аневризмы ЛЖ & $7 / 20,0$ & $7 / 23,3$ \\
\hline
\end{tabular}

В настоящее время, исходя из общепринятой стратегии комбинированной антигипертензивной терапии (КАГТ), приоритетным считают создание фиксированных комбинаций препаратов [4,23], одним из которых является фиксированная комбинация периндоприла аргинина и амлодипина бесилата (Престанс, Лаборатории Сервье, Франция). Широкий выбор сочетаний доз периндоприла и амлодипина $(5 / 5,5 / 10,10 / 5$ и 10/10 мг) упрощает тактику лечения, а также создает прекрасную возможность для лечения стабильной ИБС у больных с нормальным АД $[2,6,17]$.

Целью исследования явилась оценка противоишемического эффекта Престанса в дозе 5/5 мг/сут., его влияния на структурно-функциональное ремоделирование сердца, вазомоторную функцию пле- чевой артерии и суточный профиль (СП) АД у больных, перенесших операцию АКШ.

\section{Материал и методы}

В открытое, клиническое, рандомизированное, сравнительное исследование были включены 65 больных (37 мужчин и 28 женщин) в возрасте 45-68 лет (средний возраст 56,3 $\pm 3,5)$, перенесших АКШ в сочетании с созданием маммарно-коронарного анастомоза. У 14 (21,5\%) больных одновременно проводилась аневризмоэктомия или пластика аневризмы ЛЖ $(\mathrm{n}=11)$ и МЖП $(\mathrm{n}=3)$. Из 65 больных у $38(58,5 \%)$ в анамнезе был ИМ, в т.ч. Q-ИМ - у 29 больных. После операции АКШ прекратились ангинозные приступы или значительно сократилось их количество, а также повысилась толерантность к физическим нагрузкам (ТФН). Больные в исходном состоянии были рандомизированы на 2 сопоставимые группы (гр.) по основным изучаемым признакам (таблица 1): конт-

Таблица 2

Противоишемическая эффективность лечения в сравниваемых гр., по данным ХM ЭКГ (M $\pm \mathrm{SD})$

\begin{tabular}{|c|c|c|c|c|}
\hline \multirow[b]{2}{*}{ Показатели } & \multicolumn{2}{|l|}{$\Gamma K(n=35)$} & \multicolumn{2}{|l|}{ ОГ $(n=30)$} \\
\hline & До лечения & Лечение & До лечения & Лечение \\
\hline \multicolumn{5}{|c|}{ Количество эпизодов ишемии миокарда за сутки, $\mathrm{n}$} \\
\hline - болевой ишемии & $0,74 \pm 0,07$ & $0,67 \pm 0,05$ & $0,79 \pm 0,06$ & $0,56 \pm 0,07 * * \dagger$ \\
\hline - безболевой ишемии & $2,54 \pm 0,14$ & $2,36 \pm 0,13$ & $2,48 \pm 0,16$ & $1,73 \pm 0,12 * * * \dagger \dagger$ \\
\hline \multicolumn{5}{|c|}{ Максимальная депрессия сегмента ST, мм } \\
\hline - болевой ишемии & $1,86 \pm 0,12$ & $1,79 \pm 0,10$ & $1,81 \pm 0,13$ & $1,43 \pm 0,11^{* * \dagger \dagger}$ \\
\hline - безболевой ишемии & $1,75 \pm 0,10$ & $1,67 \pm 0,13$ & $1,72 \pm 0,11$ & $1,37 \pm 0,09 * * \dagger \dagger$ \\
\hline \multicolumn{5}{|c|}{ Продолжительность депрессии ST при болевой ишемии миокарда, мин } \\
\hline - за эпизод & $1,74 \pm 0,11$ & $1,56 \pm 0,09^{*}$ & $1,78 \pm 0,12$ & $1,25 \pm 0,08^{* * \dagger \dagger}$ \\
\hline - за сутки & $2,35 \pm 0,14$ & $2,21 \pm 0,16$ & $2,29 \pm 0,15$ & $1,65 \pm 0,10^{* *+\dagger}$ \\
\hline \multicolumn{5}{|c|}{ Продолжительность депрессии ST при безболевой ишемии миокарда, мин } \\
\hline - за эпизод & $2,09 \pm 0,14$ & $1,85 \pm 0,12^{*}$ & $2,14 \pm 0,13$ & $1,55 \pm 0,09^{* *} \dagger \dagger$ \\
\hline - за сутки & $5,27 \pm 0,32$ & $4,42 \pm 0,28 * *$ & $5,34 \pm 0,29$ & $2,61 \pm 0,18 * * * \dagger \dagger \dagger$ \\
\hline \multicolumn{5}{|c|}{ ЧСС во время ишемии миокарда, уд/мин } \\
\hline - болевой ишемии & $112,2 \pm 10,5$ & $114,0 \pm 13,1$ & $113,0 \pm 9,8$ & $127,5 \pm 10,6^{*} \dagger$ \\
\hline - безболевой ишемии & $96,4 \pm 8,2$ & $99,3 \pm 10,2$ & $95,0 \pm 7,7$ & $112,9 \pm 8,4^{*} \dagger$ \\
\hline
\end{tabular}

Примечание. ${ }^{*}$ - достоверность различий (p) показателей до и после лечения в группах: ${ }^{*}-\mathrm{p}<0,05 ; * *-p<0,01 ; * * *-p<0,001 .(\dagger)-$ достоверность различий (р) показателей после лечения в группах: $\uparrow-\mathrm{p}<0,05 ; \dagger \dagger-\mathrm{p}<0,01 ; \dagger \dagger \dagger-\mathrm{p}<0,001$. 
Динамика показателей ЭхоКГ на фоне лечения в сравниваемых гр. (M $\pm \mathrm{SD})$

\begin{tabular}{|c|c|c|c|c|}
\hline \multirow[t]{2}{*}{ Показатели } & \multicolumn{2}{|l|}{$\Gamma \mathrm{K}(\mathrm{n}=35)$} & \multicolumn{2}{|l|}{ ОГ $(\mathrm{n}=30)$} \\
\hline & До лечения & Лечение & До лечения & Лечение \\
\hline ЧСС, уд/мин & $74,3 \pm 4,5$ & $73,2 \pm 4,9$ & $73,9 \pm 4,7$ & $74,1 \pm 4,3$ \\
\hline КДО ЛЖ, мл & $143,2 \pm 8,3$ & $138,3 \pm 7,8$ & $144,5 \pm 7,9$ & $136,3 \pm 7,0$ \\
\hline КСО ЛЖ, мл & $56,1 \pm 3,6$ & $53,6 \pm 3,2$ & $55,4 \pm 3,3$ & $48,0 \pm 2,9^{*}$ \\
\hline ФВ,$\%$ & $56,3 \pm 3,0$ & $58,2 \pm 3,5$ & $55,4 \pm 2,8$ & $62,3 \pm 3,2^{*}$ \\
\hline СИ, л/мин/м² & $3,19 \pm 0,21$ & $3,28 \pm 0,24$ & $3,24 \pm 0,26$ & $3,66 \pm 0,23 * \dagger$ \\
\hline ОПСС, дин $\bullet^{\circ} \cdot \mathrm{cm}^{5}$ & $1497,2 \pm 73,4$ & $1406,1 \pm 67,4$ & $1518,2 \pm 70,4$ & $1259,7 \pm 63,1^{* *}$ \\
\hline ИММЛЖ, г/м² & $116,2 \pm 6,3$ & $112,4 \pm 5,8$ & $117,5 \pm 6,6$ & $108,6 \pm 6,4$ \\
\hline $\mathrm{Ve}, \mathrm{cm} / \mathrm{c}$ & $92,0 \pm 4,6$ & $95,3 \pm 5,2$ & $90,7 \pm 4,4$ & $98,3 \pm 2,7^{*}$ \\
\hline $\mathrm{Va}, \mathrm{cm} / \mathrm{c}$ & $95,2 \pm 5,3$ & $90,4 \pm 4,5$ & $94,2 \pm 5,6$ & $79,1 \pm 3,4^{*} \dagger$ \\
\hline $\mathrm{Ve} / \mathrm{Va}$ & $0,95 \pm 0,06$ & $1,05 \pm 0,07^{*}$ & $0,96 \pm 0,05$ & $1,24 \pm 0,08 * * * \dagger \dagger$ \\
\hline IVRT, c & $0,117 \pm 0,008$ & $0,114 \pm 0,011$ & $0,119 \pm 0,007$ & $0,102 \pm 0,009^{* * \dagger} \dagger$ \\
\hline DT, c & $0,215 \pm 0,013$ & $0,209 \pm 0,015$ & $0,213 \pm 0,014$ & $0,198 \pm 0,013$ \\
\hline
\end{tabular}

Примечание. * - достоверность различий (р) показателей до и после лечения в группах: * $-\mathrm{p}<0,05 ; * *-p<0,01 ;{ }^{* * *}-\mathrm{p}<0,001 .(\dagger)-$ достоверность различий (р) показателей после лечения в группах: $\uparrow-p<0,05 ; \dagger \dagger-p<0,01 ; \dagger \dagger-p<0,001$.

рольная группа (ГК) $(\mathrm{n}=35)$ и основная гр. (ОГ) $(\mathrm{n}=30)$. В обеих гр. больным назначали дезагреганты и статины, в ОГ - дополнительно Престанс $5 / 5$ мг/сут. Лечение Престансом проводили через 3-4 нед. после АКШ и в течение 4 мес. в условиях амбулаторно-поликлинической реабилитации.

Исследование проводили в соответствии с требованиями Хельсинской декларации Всемирной ассоциации врачей (1989); протокол исследования был одобрен этическим комитетом института. Критерием включения в исследование больных являлось наличие эпизодов ишемии миокарда, выявляемой по результатам суточного мониторирования (СМ) ЭКГ. Критериями исключения из исследования являлись: АГ; ХСН > II ФК; клапанные пороки сердца; нарушения внутрижелудочковой проводимости; противопоказания и плохая переносимость амлодипина и периндоприла; острая фаза мозгового инсульта (МИ); аритмии и блокады сердца, требующие антиаритмической терапии.

Допплер-эхокардиографию (Д-ЭхоКГ) выполняли на аппарате ALOKA 1700 SSD (Япония), оснащенном фазированным электронным датчиком, в режиме Bи М-сканирования постандартной методике. Определяли размеры полости ЛЖ - конечный систолический и конечный диастолический объемы (КСО ЛЖ, КДО ЛЖ) по формуле Teicholz L, et al., толщину МЖП и задней стенки ЛЖ (ЗСЛЖ), ФВ, сердечный индекс (СИ) и общее периферическое сосудистое сопротивление (ОПСС). Массу миокарда ЛЖ (ММЛЖ) вычисляли по формуле Devereux R, et al. Критерием гипертрофии ЛЖ (ГЛЖ) считали индекс ММЛЖ (ИММЛЖ) > 125 г/ $\mathrm{m}^{2}$ у мужчин и > 110 г/м² у женщин. Диастолическую функцию ЛЖ изучали методом Д-ЭхоКГ в импульсном режиме и по данным трансмитрального диастолического потока (ТМДП). Рассчитывали максимальную скорость быстрого и медленного диастолического наполнения $(\mathrm{Ve}, \mathrm{Va})$, их соотношение ( $\mathrm{Ve} / \mathrm{Va})$, время изоволюмического расслабления миокарда ЛЖ (IVRT) и время замедления потока в фазу раннего диастолического наполнения (DT).

Эндотелий-зависимую вазодилатацию (ЭЗВД) изучали путем создания реактивной гиперемии после 5-минутной механической компрессии плечевой артерии
(ПА) по методу Celemajer D S, et al. [8]. Величину эндотелий-независимой вазодилатации (ЭНЗВД) определяли после сублингвального приема 1 таб. нитроглицерина. Также вычисляли толщину комплекса интима-медиа (ТКИМ) и диаметр просвета общей сонной артерии (ОСА), соотношение ТКИМ к диаметру просвета ОСА относительную толщину стенки (ОТС) и пиковую систолическую скорость кровотока (Vmax).

Холтеровское мониторирование (ХМ) ЭКГ проводили с помощью аппарата Astracard® (Россия) в условиях максимально приближенных к повседневной жизни больного. В 3-х отведениях ЭКГ анализировали характер ишемической депрессии сегмента ST (болевая и безболевая ишемия), определяли количество эпизодов ишемии миокарда, максимальную величину депрессии сегмента ST и ее суммарную продолжительность за сут., а также частоту сердечных сокращений (ЧСС) во время ишемии миокарда, т. е. частотный порог возникновения ишемии. Критерием ишемии миокарда на ЭКГ считали наличие эпизодов горизонтальной или нисходящей депрессии сегмента ST на 0,1 мВ длительностью 80 мс от точки J, длящаяся 1 мин (Kodama Y., 1995).

СМАД проводили на аппарате LabBP ${ }^{\circ}$ (OOO “Петр Телегин”, Россия) и с целью исключить из исследования больных с транзиторной АГ и “гипертонией белого халата", а также для определения циркадного ритма АД и выявления эпизодов гипотензии. Измерения АД проводили с интервалами 30 мин днем (д) и 60 мин ночью (н) (22.007.00 ч.). Рассчитывали следующие показатели СМАД: среднесуточные показатели систолического и диастолического АД (САД, ДАД); степень ночного снижения (СНС) САД и ДАД; вариабельность САД и ДАД (ВарСАД, ВарДАД); индексы времени нагрузки давлением (ИВ САД, ИВ ДАД); суточный индекс (СИ); величина утреннего подъема (ВУП) САД и ДАД.

При количественной обработке результатов использовали статистическую программу Statistica версии 6.0. В зависимости от распределения на нормальность проводили вычисления, применяя параметрические критерии (t-критерий Стьюдента) и непараметрические критерии (U-критерий Вилкоксона-Манна-Уитни). Данные представлены в виде $\mathrm{M} \pm \mathrm{SD}$. Различие считали достоверным при $\mathrm{p}<0,05$. 
Динамика структурно-функциональных показателей ОСА и вазомоторной функции плечевой артерии на фоне лечения в сравниваемых гр. (M $\pm \mathrm{SD})$

\begin{tabular}{lllll}
\hline Показатели & \multicolumn{2}{c}{ ГК $(\mathrm{n}=35)$} & ОГ $(\mathrm{n}=30)$ & Лечение \\
\cline { 2 - 4 } & До лечения & Лечение & До лечения & $4,46 \pm 0,32$ \\
\hline Диаметр ОСА, мм & $4,34 \pm 0,31$ & $4,37 \pm 0,34$ & $4,28 \pm 0,29$ & $0,97 \pm 0,08$ \\
КИМ, мм & $1,03 \pm 0,06$ & $0,98 \pm 0,09$ & $1,05 \pm 0,07$ & $0,215 \pm 0,034^{*}$ \\
OTC & $0,234 \pm 0,026$ & $0,226 \pm 0,035$ & $0,237 \pm 0,028$ & $0,60 \pm 0,05^{* *} \dagger \dagger$ \\
Vmax, м/с & $0,77 \pm 0,06$ & $0,72 \pm 0,07$ & $0,74 \pm 0,08$ & $8,34 \pm 0,61^{* * *} \dagger \dagger$ \\
ЭЗВД, \% & $6,68 \pm 0,47$ & $7,04 \pm 0,56$ & $6,59 \pm 0,43$ & $19,12 \pm 1,58^{*} \dagger$ \\
ЭНЗВД, \% & $17,23 \pm 1,62$ & $17,31 \pm 2,06$ & $17,15 \pm 1,49$ & \\
\hline
\end{tabular}

Примечание. * - достоверность различий (p) показателей до и после лечения в группах: * $-\mathrm{p}<0,05 ;{ }^{* *}-\mathrm{p}<0,01 ; * * *-\mathrm{p}<0,001 .(\dagger)-$ достоверность различий (p) показателей после лечения в группах: $\uparrow-p<0,05 ; \dagger \dagger-p<0,01 ; \dagger \dagger \uparrow-p<0,001$.

Таблица 5

Динамика среднесуточных показателей СП АД на фоне лечения в сравниваемых гр. (M $\pm \mathrm{SD})$

\begin{tabular}{lllll}
\hline \multirow{2}{*}{ Показатели } & \multicolumn{3}{c}{ ГК $(\mathrm{n}=35)$} & ОГ $(\mathrm{n}=30)$ \\
\cline { 2 - 5 } САД, мм рт.ст. & До лечения & Лечение & До лечения & Лечение \\
ДАД, мм рт.ст. & $128,2 \pm 8,3$ & $124,0 \pm 7,8$ & $130,4 \pm 8,1$ & $123,5 \pm 9,3$ \\
СНС САД, \% & $86,1 \pm 6,5$ & $87,4 \pm 5,6$ & $87,4 \pm 6,0$ & $85,7 \pm 5,3$ \\
СНС ДАД, \% & $17,6 \pm 2,5$ & $19,1 \pm 3,3$ & $16,9 \pm 2,8$ & $20,4 \pm 3,1$ \\
ИВ САД, \% & $16,3 \pm 2,9$ & $17,4 \pm 3,2$ & $17,5 \pm 2,6$ & $21,4 \pm 3,4$ \\
ИВ ДАД, \% & $24,0 \pm 3,5$ & $23,8 \pm 3,3$ & $25,1 \pm 3,2$ & $18,1 \pm 3,4$ \\
Вар САД, мм рт.ст. & $21,2 \pm 2,3$ & $20,2 \pm 3,0$ & $20,8 \pm 2,7$ & $12,6 \pm 1,5 * * \dagger$ \\
Вар ДАД, мм рт.ст. & $15,3 \pm 1,5$ & $14,7 \pm 1,6$ & $15,6 \pm 1,4$ & $11,4 \pm 2,5$ \\
ВУП САД, мм рт.ст. & $12,4 \pm 2,3$ & $12,0 \pm 1,9$ & $13,1 \pm 2,2$ & $30,5 \pm 2,4 * \dagger$ \\
ВУП ДАД, мм рт.ст. & $37,5 \pm 3,4$ & $36,1 \pm 3,2$ & $36,8 \pm 2,9$ & $15,7 \pm 1,8^{*} \dagger$ \\
\hline
\end{tabular}

Примечание. ${ }^{*}$ - достоверность различий (p) показателей до и после лечения в группах: ${ }^{*}-\mathrm{p}<0,05 ;{ }^{* *}-\mathrm{p}<0,01 ;{ }^{* * *}-\mathrm{p}<0,001 .(\dagger)-$ достоверность различий (p) показателей после лечения в группах: $\uparrow-\mathrm{p}<0,05 ; \dagger \uparrow-\mathrm{p}<0,01 ; \dagger \uparrow \uparrow-\mathrm{p}<0,001$.

\section{Результаты}

Согласно данным ХМ ЭКГ, выявлено достоверное различие противоишемической эффективности терапии Престансом по сравнению с ГК (таблица 2). Величины максимальной депрессии сегмента ST болевой и безболевой ишемии миокарда на фоне лечения Престансом оказались достоверно меньше, чем в ГК: в среднем $18,0 \%$ и $16,7 \%$, соответственно $(\mathrm{p}<0,01)$. Лечение Престансом увеличивает пороговую частоту возникновения болевой и безболевой ишемии миокарда по сравнению с плацебо - в среднем на $11,8 \%$ и $13,7 \%$, соответственно $(\mathrm{p}<0,05)$, что свидетельствует о повышении коронарного резерва и улучшении ТФН.

Изучение эффективности терапии Престансом по сравнению с ГК показало значительное улучшение структурно-функциональных показателей сердца (таблица 3). Показатель КСО ЛЖ достоверно уменьшился в среднем на $13,4 \%(\mathrm{p}<0,05)$ и по сравнению с ГК оказался меньше на $11,4 \%(\mathrm{p}<0,05)$. Снижение ОПСС в ОГ в среднем на $17,0 \%(\mathrm{p}<0,01)$, в т.ч. по сравнению с ГК в среднем на $10,4 \%(\mathrm{p}<0,05)$ способствовало улучшению сократительной и насосной функции сердца. На фоне терапии Престансом $5 / 5$ мг/сут. достоверно увеличились показатели ФВ и СИ: в среднем $12,5 \%$ и 13,0\%, соответственно $(\mathrm{p}<0,05)$. Увеличение СИ в ОГ было достоверно больше, чем в ГК: в среднем на $11,6 \%$ $(\mathrm{p}<0,05)$. В ОГ отмечены наиболее выраженные изменения показателей ТМДП, свидетельствующие о достоверном улучшении активной релаксации миокарда ЛЖ. По сравнению с ГК также достоверно уменьшились показатели Va и IVRT в среднем на $12,5 \%$ и $10,5 \%$, соответственно $(\mathrm{p}<0,05)$ и, наоборот, увеличился показатель $\mathrm{Ve} / \mathrm{Va}$ в среднем на $18,1 \%(\mathrm{p}<0,01)$.

Для определения прогноза ССО и эффективности АГТ важно изучение функции эндотелия сосудистой стенки и коррекция ее нарушений $[8,18]$. Оценка влияния терапии Престансом 5/5 мг/сут. на структурно-функциональные показатели сосудистой стенки выявило достоверное уменьшение ОТС и Vmax в среднем на $9,3 \%(\mathrm{p}<0,05)$ и $18,9 \%(\mathrm{p}<0,01)$, соответственно (таблица 4). Также достоверно увеличились показатели ЭЗВД в среднем на $26,6 \%(p<0,001)$ и ЭНЗВД на $11,5 \%(\mathrm{p}<0,05)$, в т.ч. по сравнению с ГК: в среднем на $18,5 \%(\mathrm{p}<0,01)$ и $10,5 \%(\mathrm{p}<0,05)$. Показатели диаметра ОСА и ТКИМ в ОГ имели лишь тенденцию к уменьшению $(\mathrm{p}>0,05)$.

Принципиально важным является изучение влияния Престанса на показатели СП АД, особенно у больных с исходно нормальными цифрами АД. Показано, что на фоне терапии Престансом 5/5 мг/ сут. у больных с типом “dipper” сохранялся нормаль- 
ный циркадный ритм АД, а у больных с типами “nondipper" и "night peaker" отмечалось увеличение СНС АД (таблица 5). Кроме того, наблюдалась тенденция к снижению ( $>0,05)$ среднесуточных показателей САД и ДАД, ИВ САД и ДАД, особенно выраженная динамика выявлена в ОГ. Достоверным оказалось уменьшение Вар САД на фоне терапии Престансом в среднем на 19,2\% (p<0,01) и по сравнению с ГК в среднем на $14,3 \%(\mathrm{p}<0,05)$. Необходимо отметить, что Престанс в дозе 5/5 мг/сут. надежно контролирует АД в течение суток, особенно предупреждает подъем АД в ранние утренние часы. Показатели ВУП САД и ВУП ДАД достоверно уменьшились в среднем на 17,1 \% и 19,5\%, соответственно $(\mathrm{p}<0,05)$, в т.Ч. по сравнению с ГК: в среднем на $15,5 \%$ и $18,2 \%$, соответственно $(\mathrm{p}<0,05)$.

Важно отметить, что в ГК за период наблюдения у $4(11,4 \%)$ больных возник острый коронарный синдром (ОКС). В 3 случаях проводилась первичная чрескожная коронарная ангиопластика - стентирование, в 1 случае по поводу тромбоза шунта осуществлялась тромболитическая терапия (ТЛТ). В ОГ лишь у одного больного возник ОКС без подъема сегмента ST, который успешно купирован медикаментозно. В ГК больных, которым выполняли АКШ в сочетании с аневризмоэктомией или пластикой аневризмы стенки ЛЖ, в ближайшие 2-3 мес. после операции в 5 случаях из 7 наблюдалось прогрессирование СН. В ОГ ни у одного аналогичного больного развитие и/или нарастание симптомов СН отсутствовали. В послеоперационном периоде у больных обеих гр., по данным ХМ ЭКГ, выявлялись одиночные желудочковые экстрасистолы в количестве 15-60 в сут.

Необходимо отметить, что к концу периода реабилитации и в результате послеоперационной реадаптации сердечно-сосудистой системы, а также в связи с тенденцией АД к увеличению до 150 мм рт.ст. 6 больным было рекомендовано лечение Престансом 5/10 мг/сут. Это также продиктовано необходимостью добиться максимально возможного терапевтического эффекта при использовании переносимых доз препаратов, что возможно благодаря широкому спектру дозировок компонентов Престанса, облегчающему выбор оптимального режима терапии.

\section{Обсуждение}

Общепринятая тактика ведения больных после операции АКШ предусматривает применение лишь патогенетически обоснованных кардиотропных ЛП (статины, дезагреганты), поскольку для большинства ЛП после реваскуляризации миокарда отсутствует терапевтическая мишень их фармакологического действия [3]. Однако выявляемая в послеоперационный период желудочковая эктопия, тенденция к артериальной гипотензии и/или относительно низкий показатель ФВ может свидетельствовать о неадекватности реваскуляризации миокарда и/или об отсутствии должного терапевтического эффекта особенно первые месяцы после АКШ.

Показано, что у больных, перенесших операцию АКШ, наиболее характерно возникновение эпизодов безболевой ишемии миокарда. При этом эпизоды безболевой ишемии, как до лечения, так и после лечения оказались длиннее эпизодов болевой ишемии. Болевая и безболевая ишемия миокарда, выявляемые при ХМ ЭКГ, даже первые мес. после АКШ, не исключает риск развития острых сердечно-сосудистых событий (ССС). Показано, что после АКШ не полностью восстанавливается коронарный резерв, что подтверждается результатами ХМ ЭКГ. Лечение Престансом благодаря синергическим эффектам периндоприла и амлодипина улучшает эндотелий-зависимую коронарную дилатацию и диастолическую функцию ЛЖ, и тем самым, повышает коронарный резерв.

Обнаружено, что лечение Престансом 5/5 мг/ сут., начатое в ближайший послеоперационный период, особенно после АКШ в сочетании с аневризмоэктомией, положительно влияет на процессы ремоделирования ЛЖ, улучшает систолическую и/ или диастолическую функции, что объясняется увеличением коронарного кровоснабжения в зонах гибернирующего ("спящего") миокарда после хирургической реваскуляризации.

Как известно, восстановление нарушенной сократимости ишемизированного миокарда во многом зависит от соотношения зон фиброза и зон “спящего” миокарда. Гибернирующий миокард - материальный субстрат хронической дисфункции ЛЖ, возникающий в результате длительной гипоперфузии миокарда, при которой КМЦ остаются живыми, но функция их значительно снижается [14]. “Засыпание” представляет собой регуляторный механизм, позволяющий в ответ на хроническую и глубокую ишемию использовать минимальный коронарный резерв исключительно для поддержания жизнеспособности и структурной целостности миокарда. Считается, что только “спящий” миокард восстанавливает свою функцию после нормализации нарушенного миокардиального кровотока [3]. В случаях “оглушенного” миокарда компенсаторные механизмы защиты КМЦ от ишемии не могут достаточно полно сохранить их структуру, и поэтому в реваскуляризированной области функция миокарда не восстанавливается неопределенно длительный период времени [5].

Проведенное исследование показало, что Престанс в дозе 5/5 мг/сут. даже при нормальном и повышенном нормальном АД снижает избыточную Вар АД, эффективно предупреждает резкие подъемы АД в ранние утренние часы и не вызывает артериальной гипотензии. Это подтверждается результатами недавно проведенного дополнительного анализа в исследовании ASCOT-BPLA (Anglo- 
Scandinavian Cardiac Outcomes Trial - Blood Pressure Lowering Arm), которое показало, что у больных АГ комбинация амлодипина и периндоприла была более эффективной в снижении Вар САД, чем комбинация $\beta$-адреноблокатора ( $\beta$-АБ) и тиазидного Д [10]. Известно, что избыточная Вар АД является предиктором развития МИ и коронарных событий, поскольку вызывает повреждение артерий и их структурное ремоделирование, повышает сопротивление периферических сосудов [10]. Более выраженное снижение Вар АД объясняет различия по частоте МИ и коронарных событий между гр.

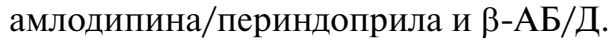

Необходимо отметить, что оба компонента комбинированного препарата Престанс - периндоприл и амлодипин обладают вазопротективным и антиатеросклеротическим действием, которое доказано также у больных, перенесших чрескожную коронарную ангиопластику $[11,12,16]$. В рандомизированном, клиническом исследовании PERTINENT (Perindopril-Thrombosis, Inflammation, Endothelial dysfunction and Neurohormonal activation Trial) терапия периндоперилом в дозе 8 мг/сут. в течение 2 лет по сравнению с плацебо достоверно снижает уровень биомаркеров атеротромбоза: С-реактивного белка (СРБ), фибриногена, фактора некроза опухоли ó и d-димера и в результате уменьшается первичная конечная точка - сердечно-сосудистая смертность, нефатальный ИМ и успешная реанимация [24]. В рандомизированном, клиническом исследовании CAPARES (Coronary AngioPlasty Amlodipine REStenosis Study) показано, что амлодипин достоверно снижает частоту рестенозов, нефатального ИМ и внезапной смерти (ВС), а также

\section{Литература}

1. Добровольский А.В. Место производных дигидропиридина в лечении заболеваний сердечно-сосудистой системы (современное состояние проблемы). РМЖ 2008; 16(11): 1599-608.

2. Карпов Ю.А. Оптимальное лечение артериальной гипертонии и ишемической болезни сердца: аргументы в пользу комбинации периндоприла аргинина и амлодипина. Cons Med 2010; 5: 51-6.

3. Клюжев В.М., Ардашев В.Н., Брюховецкий А.Г., Михеев А.А. Ишемическая болезнь сердца. М.: Медицина 2004; 202-29.

4. Российские национальные рекомендации по диагностике и лечению артериальной гипертензии. Сист гиперт 2010 ; 3: 5-26.

5. Шевченко Ю.Л., Виллер А.Г., Белевитин А.Б. и др. Особенности кровоснабжения миокарда после аортокоронарного шунтирования в раннем послеоперационном периоде. - В кн.: Тезисы докладов IV Всероссийского съезда сердечно-сосудистых хирургов. М. 1998; 71.

6. Bahl VK, Jadhav UM, Thacker HP. Management of hypertension with the fixed combination of perindopril and amlodipine in daily clinical practice. Results from the STRONG Prospective Observational Multicentre Study. Am J Cardiovasc Drugs 2009; 9 (3): 136-42.

7. Bertrand M, Sever P. Synergistic effect of perindopril and cal- почти в 3 раза число повторных коронарных ангиопластик и операций АКШ $[16,25]$.

Роль периндоприла у больных, перенесших АКШ, особенно после вмешательств по поводу постинфарктных аневризм ЛЖ, недооценима в профилактике прогрессирования СН [13]. Поэтому комбинированный препарат Престанс обладает широким спектром терапевтических эффектов, имеющих важное прогностическое значение у больных ИБС, перенесших операцию АКШ. По мере восстановления адаптационно-компенсаторных механизмов кровообращения после операции АКШ возможен переход в режим дозирования с использованием Престанса 5/10 и 10/10 мг/сут, что может служить наиболее эффективным способом кардиопротекции, а также в профилактике рестенозов и улучшении отдаленного прогноза.

\section{Заключение}

Таким образом, фиксированная комбинация периндоприла аргинина и амлодипина бесилата Престанса $5 / 5$ мг/сут. у больных стабильной ИБС и нормальным АД, перенесших операцию АКШ, обладает выраженным противоишемическим эффектом. Это обусловлено улучшением ЭЗВД, диастолической функции ЛЖ и сократительной способности миокарда. Престанс поддерживает нормальный циркадный ритм АД, снижает избыточную Вар АД и не вызывает эпизодов нагрузки гипотензией. Престанс $5 / 5$ мг/сут. как стартовая терапия является эффективным и безопасным препаратом в профилактике ОКС и/или ИМ, а также прогрессирующей $\mathrm{CH}$ в ближайшие мес. после АКШ.

cium channel blockers in prevention of cardiac events and death in coronary artery disease patients: analysis from the EUROPA study (abstract 3267). Congress of the European Society of Cardiology (ESC). Munich, 2008.

8. Celermajer DS, Sorensen KE, Gooch VM, et al. Non-invasive detection of endothelial dysfunction in children and adults at risk of atherosclerosis. Lancet 1992; 340: 1111-5.

9. Costanzo P, Perrone-Filardi P, Petretta M, et al. Calcium channel blockers and cardiovascular outcomes: a meta-analysis of 175634 patients. Hypertens 2009; 27: 1136-51.

10. Dahlof B, Sever PS, Poulter NR, et al. Prevention of cardiovascular events with an antihypertensive regimen of amlodipine adding perindopril as required versus atenolol adding bendroflumethiazide as required in the Anglo-Scandinavian Cardiac Outcomes Trial. Blood Pressure Lowering Arm (ASCOT-BPLA): a multicentre randomized controlled trial. Lancet 2005; 366: 895-906.

11. Dens J, Desmet W, Piessens J. An updated meta-analysis of calcium-channel blockers in the prevention of restenosis after coronary angioplasty. Am Heart J 2003; 145 (3): 404-8.

12. Doggrell SA. Has the controversy over the use of calcium channel blockers in coronary artery disease been resolved? Expert Opin. Pharmacotherapy 2005; 6 (5): 831-4.

13. Ferrari R. for the PREAMI investigators. Effects of ACE inhibition with perindopril on left ventricular remodeling and clinical outcome. Arch Intern Med 2006; 166: 659-66. 
14. Gunning M, Chua T, Harringhton D, et al. Hibernating myocardium: clinical and functional response to revascularization. Eur J Cardiothorac Surg 1997; 11: 1105-12.

15. Jamerson KA, Weber MA, Bakris GL, et al. On behalf of the ACCOMPLISH investigators Benazepril plus amlodipine or hydrochlorothiazide for hypertension in high-risk patients. $\mathrm{N}$ Engl J Med 2008; 359: 2417-28.

16. Jorgensen B, Simonsen S, Endresen K. Restenosis and clinical outcome in patients treated with amlodipine after angioplasty: results from the Coronary AngioPlasty Amlodipine REStenosis Study (CAPARES). JACC 2000; 35(3): 592-9.

17. Ker J. Combination treatment for hypertension. SA Fam Pract 2010; 52 (5): 417-21.

18. Koh KK, Han SH, Ahn JY, et al. Amlodipine improves endothelial function and metabolic parameters in patients with hypertension. Int J Cardiol 2009; 133 (1): 23-31.

19. Nissen SE, Tuzcu EM, Libby P, et al. Effect of antihypertensive agents on cardiovascular events in patients with coronary disease and normal blood pressure: the CAMELOT study: a randomized controlled trial. JAMA 2004; 292 (18): 2217-25.

20. Pitt B, Bryington RP, Furberg CD, et al. Effect of amlodipine on the progression of atherosclerosis and the occurrence of clinical events. PREVENT Investigators. Circulation 2000; 102:
1503-10.

21. Rodriguez-Granillo GA, Vos J, Bruining N, et al. Long-term effect of Perindopril on coronary atherosclerosis progression (from the PERindopril's Prospective Effect on Coronary aTherosclerosis by Angiography and IntraVascular Ultrasound Evaluation (PERSPECTIVE) Study. Am J Cardiol 2007; 100: $159-63$.

22. The EUROPA investigators. Efficacy of perindopril in reduction of cardiovascular events among patients with stable coronary artery disease: randomized, double-blind, placebo-controlled, multicentre trial (the EUROPA study). Lancet 2003; 362; 782-8.

23. The Task Force for the management of arterial hypertension of the European Society of Hypertension and of the EUROPEAN Society of Cardiology. 2007 Guidelines for the management of arterial hypertension. J Hypertens 2007; 25: 1105-87.

24. Ceconi C, Fox KM, Remme WJ, et al. ACE inhibition with perindopril and biomarkers of atherosclerosis and thrombosis: Results from the PERTINENT study. Atherosclerosis 2009; 204: 273-5.

25. Недогода С.В. Применение антагонистов кальция для профилактики сердечно-сосудистых осложнений при операциях на сердце. РФК 2006; 3: 56-64.

Поступила 27/05-2011 